\title{
Usage and Perceptions of Social Media Tools among Higher Education Instructors
}

\author{
Omar Alshehri
}

\begin{abstract}
This paper tried to investigate the current situation of using social media as tools for e-learning to support learning at an emerging university in the south of Saudi Arabia. It also examined the benefits of using social media tools in higher education and the important role that these tools can play to facilitate the educational process. Additionally, the barriers that lecturers could face during the use of social media tools in the educational process were examined. Participants in this study were 10 lecturers. Semi-structured interviews were used to collect data for this study. The results indicated that some of the interviewees had very positive attitudes towards using social media as tools for e-learning and felt that these tools were extremely effective instructional tools and should be integrated into the university curricula and that tutors should start using them as tools to aid the other learning environments. However, the results indicated that the major barriers to using these tools in learning were a distraction, opposing Islamic religious teachings, privacy issues, and cyberbullying. The study recommended that this study could be replicated at other Saudi universities to investigate factors and barriers that might affect Saudi students' attitudes toward using social media to support learning.
\end{abstract}

Index Terms-Saudi Arabia, social media tools, higher education, advantages of social media use, disadvantages to social media use.

\section{INTRODUCTION}

The growing importance of social media tools and its influence on teaching and learning has brought about significant changes in the academic environment in the Kingdom of Saudi Arabia. Social media is one of the most prominent inventions of the twenty-first century. There are many social media applications that have become a part of daily life including YouTube, WhatsApp, Facebook, Twitter, and Wikipedia.

Social media tools have become tools in the hands of the present generation of students. Ref. [1] mentioned "They use digital technology transparently, without even thinking about it" [p. 15]. Of course, educators understand there is a value in technology and begun to harness these inventions for educational purposes. Therefore, studies have proven the significance of integrating social media for facilitating teaching and learning in higher education [2]. Moreover, social media can provide an opportunity for students to acquire the skills of communication, collaboration, critical thinking, creativity, and life-long learning [3]. However, there

Manuscript was received March 11, 2019; revised April 15, 2019. The work has been carried out by self-financing basis with academic research in focus

O. A. Alshehri is with the University of Glasgow, UK (tel.: 447454625470; e-mail: o.alshehri.1@ research.gla.ac.uk). is a hesitancy to incorporate different modes of social media: "While educators may recognize the value of incorporating technology into the classroom, many may struggle to identify ways to use technology toward extending students' thinking, rather than as an add-on to a lesson" [4, p. 24].

Education in Saudi Arabia is undergoing a profound change to be compatible with the current revolution in educational technology. Therefore, the Ministry of Education has worked to encourage students and teachers to use appropriate modern tools in the educational process in order to develop self-education, cooperative, knowledge-building and knowledge-exchange. However, there is a shortage of studies that have been conducted in Saudi universities regarding the Saudi lecturers' attitudes towards adopting social media as a tool of e-learning to support learning. Thus, this research aims to understand the existing reality of using social media tools in e-learning at the emerging university to help the tutors get a better understanding of their students' attitudes, expectations, practices, and barriers that they might encounter when utilizing these modern tools.

\section{LITERATURE REVIEW}

\section{A. Lecturers' Attitudes}

Ref. [5] defines attitude as, "the degree to which a person has a favorable or unfavorable evaluation or appraisal of the behavior in question" [p. 188]. Teachers revealed positive attitudes towards using social media as tools for e-learning as using new technology motivates and increases students' attention and curiosity towards knowing [6]. They argued that utilizing new technology may improve lessons because web-based materials contain a lot of images, videos and sound recordings that can be saved on the desktop and be referred to anytime. They also believed that the integration of social media in e-learning will enhance communication and collaboration among students and academicians [7]. In a qualitative study, [8] found that teachers felt social media made their classrooms more interactive and allowed their students more quality opportunities to communicate and collaborate and improve teacher-to-student communication. Likewise, [9] found that $60 \%$ of their 137-participant sample felt that social media would improve student-to-teacher interactions.

\section{B. Social Media Categories in Higher Education}

Social media tools have become increasingly popular as learning and teaching resource in higher education, providing teachers and students with increased opportunities for educational engagement. Ref. [10] explained that social media includes resource-sharing technology which helps the 
user to carry out their work in an easy and efficient manner and enables users to engage with each other. Ref. [11] have argued for the usefulness of utilising social media in higher education and the important role that Facebook can play in classrooms. They concluded that "the evidence presented reinforces the view that such networks have untapped potential capable of making a significant contribution to the learning and teaching process," [p. 1]. Similarly, [12] found that Facebook, Wikipedia, and YouTube are the top three social media tools most used as a learning resource because they bring social engagement, communication, the speed of feedback and relationship building. Additionally, [13] argued that relationships formed via social media tools between university tutors and students open up new avenues of communication and result in an enhanced learning environment. Ref. [14] added that using social media tools, such as Facebook, builds strong relationships among tutors and students and helps develop self-confidence. It also enhances direct communication, thereby increasing the speed of feedback, while supporting students and facilitating learning among peers.

Furthermore, [15] examined the use of WhatsApp in a South African university. The students gave positive feedback and claimed that it was an easier way to communicate with their teachers and the rest of the class and that it was also fun. Moreover, an investigation conducted by [16] found YouTube to be a vital instrument for educating and learning. Indeed, more than $80 \%$ of respondents stated that they used social media tools for personal, professional, and academic purposes. Adding to that, [17] claimed that YouTube increased participation, productivity, and improved students' digital skills. Another mode of social media that has been shown to be used successfully in classrooms is Twitter. Ref. [18] conducted a quantitative study to explore undergraduates' perceptions about using Twitter as a pedagogical tool. The result indicated that Twitter provided space and opportunities to engage in academic activities. Similarly, [19], [20] concluded that Twitter allowed students to participate and extend discussion with each other in class and outside of class to gather knowledge and news and connect with professionals in their field. Additionally, [21] revealed that Wikipedia allows students to interact with the other synchronously and asynchronously, collaboratively solve problems at their own pace, provide immediate feedback to each other, clarify misunderstandings, and construct their knowledge objects. In the same vein, [22] argued that participants use social media tools such as Wikipedia to complete their tasks and develop new knowledge while collaborating with one another.

\section{Social Media Platform Use in Saudi Arabia's Higher Education}

The use of social media tools for education in Saudi Arabia is still in its early stages, although some Saudi Arabian universities have started providing such services for their university tutors and students. Saudi teachers believed that using social media as a tool for e-learning gave them more flexibility to access online resources which allow them to work and learn more independently compared to the traditional method of learning. In quantitative research conducted by [23] to study the usage of a variety of social media applications by higher education institutions in Saudi Arabia findings indicated that the use of social networking applications is quite prevalent among major Universities in Saudi Arabia especially with major and popular applications like Facebook, Twitter, YouTube, and WhatsApp. Additionally, [24] conducted a quantitative study involved 308 participants to examine the use of social media tools and their impact on knowledge sharing and learning performance by tertiary students, at a University in Saudi Arabia. The results of the study imply that the use of social media tools for chatting and discussion and for file sharing is becoming common among university teachers and students, and this positively affects knowledge sharing and impact student learning to improve their learning.

However, some barriers to using social media tools exist in certain universities. For example, some participants were concerned about privacy and security in these tools. Likewise, [25] emphasised in her study that reported that one factor that discourages the tutors from using social media in their teaching environments is the distractions that students were exposed to which prevents the learners from focusing on the course content. She also found that the tutors at King Abdul-Aziz University reported their students do not take the integration of social media technologies into the learning environments seriously.

\section{RESEARCH METHODOLOGY}

\section{A. Purpose of the Study}

The purpose of the interviews was to study the current reality of using social media as tools for e-learning by lecturers as well as discover their objections or hesitations to implementing them.

\section{B. Sample}

The sample of this study was 10 instructors, 5 males and 5 females from the College of Education in the emerging university. The sample involves a wide range of instructors from different levels of study.

\section{Evaluation Tool}

The interview consisted of ten main questions; some questions had several sub-questions. The interviews sought more in-depth data about social media tools that are not available in the emerging university, what the tutors know about these tools and whether they wish to use them with their students, and the advantages and the disadvantages social media tools. The interview also focused on the possibility of using social media tools in Saudi Arabia higher education. They were asked whether or not they were willing to improve or increase this use, with a justification for each answer.

\section{Data Analysis}

The qualitative data in this research was obtained from semi-structured interviews. Thematic analysis was applied to this qualitative data. The interviews data was coded and analysed through adapting the framework of [3] which stated that "In different texts, the approaches to analysis of qualitative data vary slightly, but we believe they can be 
described in three stages 1) organizing and familiarizing, 2) coding, and 3) interpretation of the data" (p.481). Moreover, the interviews were conducted by using the Arabic Language because it is the official language of the participants of the current research. As a result, the researcher added the translation to the previous steps so that the analysis process is clear and consistent. A total of four broad themes emerged during the process of analysis of interviewee's responses and data collected from the interviews. Interviewees gave responses regarding the existing reality of using social media as e-learning tools at the emerging university from the viewpoint of tutors. The themes that emerged included: a) the perceptions, b) types of social media tools and its extent of use for learning, c) training, and d) the problems associated with the use of social media as e-learning tools.

\section{RESULTS AND FINDINGS}

\section{A. Attitudes of Using Social Media as e-Learning Tools}

Analysing quantitative data collected has shown that the vast majority of academics participating in this research have positive perceptions towards employing social media as an e-learning tool into their interactions with their colleagues and students despite they indicated some concerns to integrate these platforms in education. It is important, however, to notice that not all the tutors agree on using social media as a learning tool. There were some who were completely opposed to using social media.

Teachers views revealed a relationship between the usefulness of social media as an e-learning tool and their positive feelings. Many tutors in this current research reported their desire to use social media in all the courses they take. As a matter of fact, when one of the participants was asked if he prefers using social media in learning, he said: "yes, I use it and like it and want to try using it in other courses." [Respondent: 7]. Another participant declared in the interview that "she wished that all the instructors used social media in their classes." [Respondent: 4). This finding is not new to research in this field as [5] found that the perceived usefulness and ease of use of social media platforms will affect attitudes towards its use.

Furthermore, the interviews data analysis revealed that social media platforms are effective for building participation, interaction, collaboration, and communication among students and instructors. Six out ten of the participants stated that these tools can extend the opportunity for class members to interact beyond formal sessions. A participant at the interviews explained that "social media applications provide a great channel to interact with lecturers and students by asking questions or discussing topics related to lessons to increase the engagements and extend conversations" [Respondent: 1]. Ref. [6] emphasised the potential of social media sites to increase interaction and networking between teachers and students as well as to co-create content in and out of the classroom.

In addition, most of the participants declared that social media tools empower learners to take charge of their own learning and develop it prompting them to select resources to create, organize and package learning content to learn effectively and efficiently. This was confirmed by one tutor during the interview when he mentioned that "social media platforms encourage learners to become effective self-regulated learners to gain competence, knowledge, support social interaction in group work, and acquire basic and complex personal knowledge management skills." (Respondent: 8). This result is consistent with findings [11]-[16], that displayed that social media platforms are a pedagogical and technological vehicle for supporting students' self-learning and the goal of the students shifts from a recipient of information to a collector, organizer, and designer of one's own learning experience.

On the other hand, at the interviews, four participants reported their opposition of using social media platforms in education. Interviewee 3, 5, and 9, for example, found that it difficult for most students to focus on their learning without making use of social media. One of them said "I noticed that students do not listen in class, they are busy chatting and reading stories online. They waste their time chatting with friends and families; instead of reading and practicing what they have learned in school" [Respondent:10]. They were explicit about their opposition to the use of social media as a tool for e-learning; they gave many reasons for their negative perceptions. Apprehension, lack of confidence and competence, and phobia about social media tools are the main reasons for favouring traditional learning methods. The teachers who were completely opposed to using social media in the classroom took issue with social media already being a distraction from everyday interactions among individuals. To them, intentionally bringing distractions into the classroom was unacceptable.

\section{B. Types of Social Media Tools and Its Extent of Use for Learning}

WhatsApp, Twitter, and YouTube were the social media applications identified as being more used by the participants. Six out of the ten participants reported that they use social media to communicate with students in extracurricular organizations. For instance, P 7 and 6 connected with their students and announced homework information through WhatsApp group. In a similar way, P 10 pointed out that she "used Twitter and WhatsApp more than the other platforms [and had] found great benefits with students and colleagues." She further suggested that these particular tools had made it "faster and easier to communicate, to learn, and to teach" [Respondent: P 10]. Undoubtedly using social media as e-learning tools will increase the chance of creating learners with many skills such as develop ideas, making arguments, exchanging opinions, and developing critical thinking. P 7 reported that "I have used Twitter with my students that I make it optional, and I found that it is great to give students more spaces to upload and share images, videos, and ideas to discuss each other's posts through audio, video or text comments" [Respondent: P 7]. In the same vein, $P$ revealed that I have found that using WhatsApp gives students a lot of options and flexibility in how to present themselves and in how to interact with a learning activity set up by their tutors or between them" [Respondent: P 8]. This emphasised that social media tools are now influencing all the different aspects of education wherein it gives good enhancement for student's 
education.

Throughout the data collection process, YouTube was an attractive platform for several academics involved in this research. Most of the interview's participants confirmed that videos stimulate classroom discussion, reinforce lectures and reading, provide a common base of knowledge among students, and help teachers teach more effectively. Videos can be powerful educational tools, but only when they are used as a means of achieving thoughtfully selected educational objectives. They agreed that videos as important learning tools provide an opportunity for students to learn in a variety of ways. For example, P 7 reported that "I have used short videos from YouTube before starting to explain the lesson. This gives students chances to think, brainstorming, argue, and collaborate to share their views regarding the topic that we discuss" [Respondent: P 7]. Similarly, P 1 observed, "The one that I use the most is YouTube because it has a lot of video clips and it supports the lesson with auditory and visual stimulus and thus is effective for the teaching and learning process" [Respondent: $\mathrm{P} 1$ ). This is in line with the studies of [7], [8]-[25], that indicated that Twitter, WhatsApp, and YouTube were by far the most used social media tools for instructional sharing by tutors in the United States.

\section{The Need for Training in the Use of Social Media as e-Learning Tools}

Most interviewees (six out of the ten participants) had no knowledge of the training offered in the emerging university, regarding the use of social media as e-learning tools. They reported that although annual workshops were held at the emerging university on the use of technology, these did not focus on the use of social media tools such as Facebook, Twitter, WhatsApp, Wiki, Skype, Myspace, and Instagram as instructional tools. One participant said, "No sufficient or professional training" [Respondent: P 7]. Another one stated, "I have attended several workshops for e-learning, but the trainers were not professionals" [Respondent: $\mathrm{P}$ 6]. Additionally, some problems relating to the organisational aspect of training programs were raised by participants. They indicated that the training and workshops sessions are held at limited times, which are incompatible with the work circumstances of academics. P 10 stated, "There are few options of times to attend training programs... the available training is in unsuitable for my time commitments" [Respondent: P 10]. On the other hand, six out of ten of the participants emphasised that the training programs and workshops are not announced in a way that encourages everyone to attend them. One participant said, "The announcements about training are usually late and training is conducted in insufficient time, with no encouragement to attend" [Respondent: P 3]. Meanwhile, one of the participants highlighted the lack of financial and moral incentives to attend the training courses, "It is additional hard work without sufficient financial incentives" [Respondent: P 8]. This result is in line with the same ideas that came from the studies done by [6]-[22] who stated that lack of training was considered by many teachers as hindrances which have a direct effect on tutors' confidence to adapt these tools for learning.

D. The Disadvantages Related to the Use of Social Media

\section{as Tools for e-Learning}

Participants noted that potential impediments to the anticipated future growth of social media are the barriers which are currently preventing faculty from engaging to a greater extent with students and each other through social media. These concerns include distraction, disrupt the enhancement of cognitive skills of the users, and cyberbullying. Most of the participants mentioned that learners can be easily distracted from lessons when they use those tools during classes to watch videos on YouTube or browse messages on Twitter, Facebook, and WhatsApp. They also stated that even when tutors use these tools in class to enhance learning, the students may use them for unintended purposes such as to play games and chat with friends. As one participant stated, "If students were allowed to use social media tools in classes, these tools may be misused and lead to distraction during lessons" [Respondent: P 3].

In addition, six out of the ten participants thought that social media tools hinder the development of cognitive and critical thinking skills. They referred that learners depended on Google to get the answer directly despite the fact that the information contained therein was often not verified or trustworthy. This was supported by another participant who remarked that "she did not know whether the students had learned anything from the lessons taught since they simply copied other people's answers and skipped the process of thinking and brainstorming, which are so important for enhancing their understanding of the concepts taught in classes" [Respondent: P 2].

Furthermore, six of the ten tutor participants stated that some of the hindrances to the adoption of social media tools in the classroom stem from the risks inherent in student internet usage. They pointed out that some students used their iPads, iPhones, and computers to reach unethical websites or inappropriate material where they feared they may encounter online sexual predators. They expressed concern that social media use in the classroom, if not managed properly, could result in inappropriate behavior and posts by students. This worried many of them. Therefore, they reported that social media tools have negative impacts. For example, one of the opponents of using social media in education noted the cases of cyberbullying among students. "Some of my students complained about their peers misusing social media to attack and abuse them" [Respondent: $\mathrm{P}$ 1]. These results are in line with the same ideas that came from the studies done by [1] -[23] who stated that distraction, disrupt the enhancement of cognitive skills of the users, and cyberbullying were considered by many teachers as hindrances which have a direct effect on tutors' confidence to adapt these tools for learning.

\section{CONCLUSION}

The purpose of this study was to examine the perception of instructors at an emerging university in Saudi Arabia to use social media as a tool for learning and how they integrate those tools for learning to make use of all the possible learning benefits that social media tools could offer to enhance teaching practice. This study concluded that 
instructors had positive perceptions of employing social media tools for learning in their interactions with their colleagues and students, although they indicated some concerns as to how to integrate these tools in education. Instructors believe that social media tools are effective for building participation, interaction, collaboration, and communication among students and tutors. Accordingly, they agreed that using social media in teaching increases student-tutor interactions. They stated that these tools have the ability to extend the opportunity for class members to interact beyond formal sessions. Additionally, most of the learners in this study indicated that they preferred using social media tools to support their learning by sharing content related to the subject of study or relevant to their areas of interest. However, it is important to mention that the problems associated with the use of social media as tools for e-learning may affect their successful implementation in education as this may influence or discourage students and tutors from taking advantage of these technologies. Consequently, providing appropriate environments in which to use these modern tools will facilitate learning for everyone.

As highlighted in the literature review, the dominant style of teaching in Saudi Arabia is the lecturing method, whereby students, for the most part, have no role to play, except to listen to and memorise what the teacher provides. The possibility of giving students an opportunity to discuss and share opinions with the whole class is very limited due to the school curriculum, the high number of students in the class, the lecture time, and also the lack of training in different teaching methods. Therefore, introducing social media tools into academic settings in a formal manner would give rise to a fundamental change in teaching methods and learning styles at the emerging university. Accordingly, this study confirmed that using social media as a tool for learning would support collaborative learning methods, generate and improve the content of students and tutors, enhance students' and tutors' communication skills and self-learning, and encourage critical and reflective thinking. Indeed, an awareness of such benefits would encourage students and tutors to use social media as a tool for learning.

\section{REFERENCES}

[1] H. A. Aifan, Usage of Social Media Technologies by Saudi Instructors at King Abdul-Aziz University to Support Students' Learning, vol. 5, no. 6, pp.74-76, 2016.

[2] I. Ajzen, "The theory of planned behavior," Organizational Behavior and Human Decision Processes, vol. 50, no. 2, pp. 179-211, 1991.

[3] D. Ary et al., Introduction to Research in Education, 7th Ed. Belmont, CA: Thompson Wadsworth, 2006.

[4] H. A. Alsurehi and A. A. A. Youbi, "Towards applying social networking in higher education: Case study of Saudi Universities," International Journal of Academic Research, vol. 6, no. 5, pp. 221-229, 2014.

[5] V. Balakrishnan and H. S. Loo, "Social media in e learning: An empirical analysis among students and academicians," GSTF Journal on Computing (JoC), vol. 2, no. 4, 2018.

[6] A. Bere, "Using mobile instant messaging to leverage learner participation and transform pedagogy at a South African University of
Technology," British Journal of Educational Technology, vol. 44, no. 4, pp. 544-561, 2013.

[7] K. Bista, "Is Twitter a pedagogical tool in higher education? Perspectives of education graduate students," Journal of the Scholarship of Teaching and Learning, vol. 15, no. 2, p. 83, 2015.

[8] A .Brailas et al., "Wikipedia in education: Acculturation and learning in virtual communities," Learning, Culture and Social Interaction, vol. 7, pp. 59-70, 2015.

[9] B. H. Capo and A. Orellana, "Web 2.0 technologies for classroom instruction: High school teachers' perceptions and adoption factors," Quarterly Review of Distance Education, vol. 12, no. 4, pp. 235-253, 2011.

[10] N. Dabbagh and A. Kitsantas, "The role of social media in self-regulated learning," International Journal of Web Based Communities, vol. 9, no. 2, pp. 256-273, 2013.

[11] V. A. Dickie and H. Meyer, "The Facebook tutor: Networking education," Ubiquitous Learning: An International Journal, vol. 8, no. 2, pp. 1-12, 2015.

[12] M. I. Eid and I. M. Al-Jabri, "Social networking, knowledge sharing, and student learning: The case of university students," Computers \& Education, vol. 99, pp. 14-27, 2016.

[13] F. Gao, T. Luo, and K. Zhang, "Tweeting for learning: a critical analysis of research on microblogging in education published in 2008e2011," British Journal of Educational Technology, vol. 43, no. 5, p. 783e801, 2012.

[14] I. Jukes, "Understanding the digital generation," Kelowna: 21st Century Fluency Project, 2010.

[15] A. Hickerson and A. Kothari, "Learning in public: Faculty and student opinions about social media in the classroom," Journalism \& Mass Communication Educator, vol. 72, no. 4, pp. 397-409, 2017.

[16] W.-H. Huang and K. Nakazawa, "An empirical analysis on how learners interact in wiki in an online graduate level learning technology course," Interactive Learning Environment, vol. 18, pp. 233-244, 2010.

[17] J. Lee et al., "Perceptions of teachers and students towards the educational application of SNS and its educational effects in middle school class," Turkish Online Journal of Educational Technology, vol. 14, no. 4, pp. 124-134, 2015

[18] Y. Liu, "Social media tools as a learning resource," Journal of Educational Technology Development and Exchange, vol. 3, no. 1, p. 101e114, 2010.

[19] Y. H. Lo, What is the participant learning experience like using YouTube to study a foreign language? 2012.

[20] Shropshire and Tytler, "So much more than selfies: Twitter for publication and "OwnVoices narratives," International Journal of Information and Education Technology, vol. 9, no. 2, pp. 159-163, 2019.

[21] A. E. Sobaih and M. Moustafa, "Speaking the same language: the value of social networking sites for hospitality and tourism higher education in Egypt," Journal of Hospitality \& Tourism Education, vol. 28, no. 1, p. 46e56, 2016.

[22] C. J. Stufft, "It started with an iced cappuccino: Social media and social good," A Journal of the Texas Council of Teachers of English Language Arts, vol. 43, no. 2, pp. 23 28, 2013.

[23] C. Sugimoto et al., "Friend or faculty: social networking sites, dual relationships, and context collapse in higher education," First Monday, vol. 20, no. 3, 2015 .

[24] W. Zakharov et al., Learning and Knowledge Analytics in Open Education, pp. 149-169, 2017.

[25] G. Zgheib, "Social media use in higher education: An exploratory multiple-case study," Doctoral dissertation, George Mason University, 2014.

Copyright $\odot 2019$ by the authors. This is an open access article distributed under the Creative Commons Attribution License which permits unrestricted use, distribution, and reproduction in any medium, provided the original work is properly cited (CC BY 4.0).

Omar A. Alshehri is a Ph.D. candidate at the University of Glasgow (UK) studying the reality of using social media as tools for learning in Saudi Arabian higher education. He has done his master's degree from the Eastern Washington University in the U.S.A. in 2013. 